\title{
Modeling and Analysing the Tensile Behavior of Fabric Samples
}

\author{
László Mihály Vas ${ }^{1}$, Fatma Göktepe ${ }^{2}$, Péter Tamás ${ }^{3}$, Marianna \\ Halász ${ }^{4}$, Dicle Özdemir ${ }^{5}$, Lívia Kokas Palicska ${ }^{6}$, Norbert \\ Szakály ${ }^{7}$
}

1 Budapest University of Technology and Economics, Faculty of Mechanical Engineering, Műegyetem rkp. 3, H-1111 Budapest, Hungary, vas@pt.bme.hu

2 Namik Kemal University, Çorlu Engineering Faculty, Department of Textile Engineering, Silahtar Mahallesi, Sinan Dede Mevkii, Çerkezköy Yolu, 3. km, 59860 Çorlu, Tekirdağ, Turkey, fgoktepe @ mmf.sdu.edu.tr

3 Budapest University of Technology and Economics, Faculty of Mechanical Engineering, Müegyetem rkp. 3, H-1111 Budapest, Hungary, tamas@inflab.bme.hu

4 Budapest University of Technology and Economics, Faculty of Mechanical Engineering, Müegyetem rkp. 3, H-1111 Budapest, Hungary, halaszm@pt.bme.hu

5 Süleyman Demirel University, Engineering \& Architecture Faculty, Department of Textile Engineering, 32260 Çünür, Isparta, Turkey, dicle @ mmf.sdu.edu.tr

6 Óbuda University, Rejtő Sándor Faculty of Light Industry and Environmental Protection Engineering, Doberdó ú. 6, H-1034 Budapest, Hungary, kokas.livia@rkk.uni-obuda.hu

7 Budapest University of Technology and Economics, Faculty of Mechanical Engineering, Müegyetem rkp. 3, H-1111 Budapest, Hungary, szakaly@mogi.bme.hu

Abstract: This paper presents a structural-mechanical model for describing the tensile behavior of textile fabrics in main directions based on the fiber-bundle-cells modeling theory and method. The applicability of this model, created by a variable transformed Ebundle shifted along the deformation axis, was demonstrated by analyzing the tensile loaddeformation behavior and the breaking process including some size effects of a plain woven fabric made of $O E$ rotor cotton yarns.

Keywords: tensile behavior of textile; modeling of textile; structural mechanical model; fiber-bundle-cells modeling; size effect of fabric samples 


\section{Introduction}

Fibrous structures such as textile materials, fiber reinforced composites, and linear polymers are built up of discrete fiber-like elements such as textile or reinforcing fibers or yarns. The adjoining fibers or those intersecting a cross section of a fibrous sample create certain small assemblies that are fiber bundles in which the fibers show collective group-behavior [1-9]. The fiber bundle can be treated as intermediate elements of a fibrous structure, which can represent the statistical properties of the geometry or the strength.

In addition to the classic one [1], L.M. Vas et al. [4-9] have introduced some other idealized statistical fiber bundles called fiber-bundle-cells (FBC), and developed a modeling method as well as a software called FiberSpace [10-16], and shown that they can be applied to modeling some structural and strength properties of fibrous materials.

In this paper, a FBC model for describing the tensile behavior and breaking process of textile fabrics in main directions is presented and demonstrated in the case of a plain fabric made of OE rotor cotton yarns.

\section{Fiber Bundle Cells-based Modeling Method}

\section{Statistical Fiber Bundle Cells}

Fibers in a fibrous structure can be classified according to their geometry (shape, position) and mechanical behavior (strain state, gripping). These fiber classes are called fiber bundle cells (FBCs) (Fig. 1) [4-9].

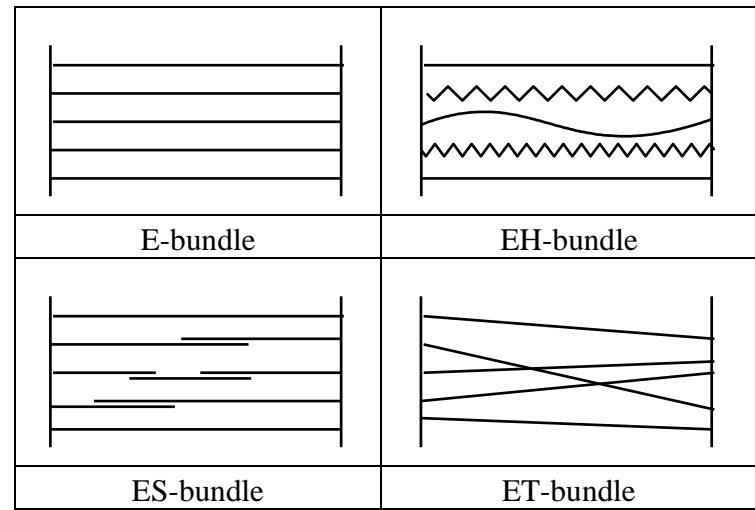

Figure 1

Structural scheme of the idealized fiber bundle cells 
Fibers of these FBCs are supposed to be perfectly flexible and linearly elastic and to break at a random strain $\left(\varepsilon_{\mathrm{S}}\right)$. They are straight in the E-bundle, loose $\left(\varepsilon_{0}<0\right)$ or pre-tensioned $\left(\varepsilon_{0}>0\right)$ in the EH-bundle, and oblique (fiber angle $\beta \neq 0$ ) in the ETbundle, and they are gripped ideally in these cases. Fibers in the ES-bundle are straight but they may slip out of their grip at a strain level $\left(\varepsilon_{\mathrm{b}}<\varepsilon_{\mathrm{S}}\right)$ or create fiberchains with slipping bonds. The shape, position, and strength parameters of fibers are assumed to be independent stochastic variables.

Considering a constant rate elongation tensile test, the tensile force $(F(u))$ creates a stochastic process as a function of the bundle strain $(u)$. Being aware of the relationship between the bundle $(u)$ and fiber strains $(\varepsilon)$, the expected value of the tensile force of the FBCs ( $E(F)=\bar{F}$ ) can be calculated as the sum of the single fiber forces using the suitable formulas developed [4-9]. Dividing the expected value by the mean breaking force of the fibers, the normalized tensile force of a bundle is computed as follows:

$$
0<F H(z)=F(z) / n F_{S} \leq 1, \quad z=u / \varepsilon_{S}
$$

where $n, F_{S}$, and $\varepsilon_{S}$ are the number, the mean breaking force and strain of fibers, respectively, and $\mathrm{z}$ is the bundle strain normalized by the mean breaking strain of the fibers. Fig. 2 shows the graphic relationship between the strain of individual flexible fibers and the bundle.

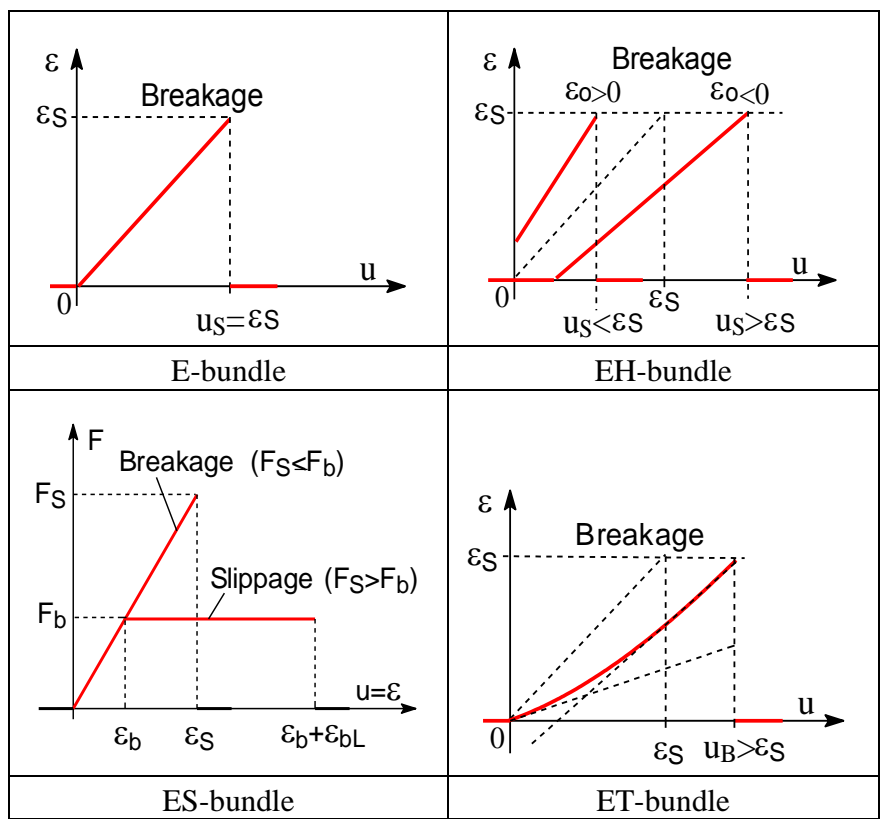

Figure 2

Relationship between the strains of single fibers and FBCs 
In the case of an ES-bundle, $\varepsilon_{\mathrm{bL}}$ is the relative slippage way of fibers. In Fig. 3, the typical normalized expected value processes calculated at different parameter values are plotted for the FBCs. For the numerical calculations, all random parameters were assumed to be of normal distribution.

From Fig. 3 it is obvious that the FBCs can model rather complicated mechanical behaviors such as the initial convex part caused by crimped fibers (EH-bundle) or the slippages generated plateau beyond the peak (ES-bundle) even if they are used in themselves.

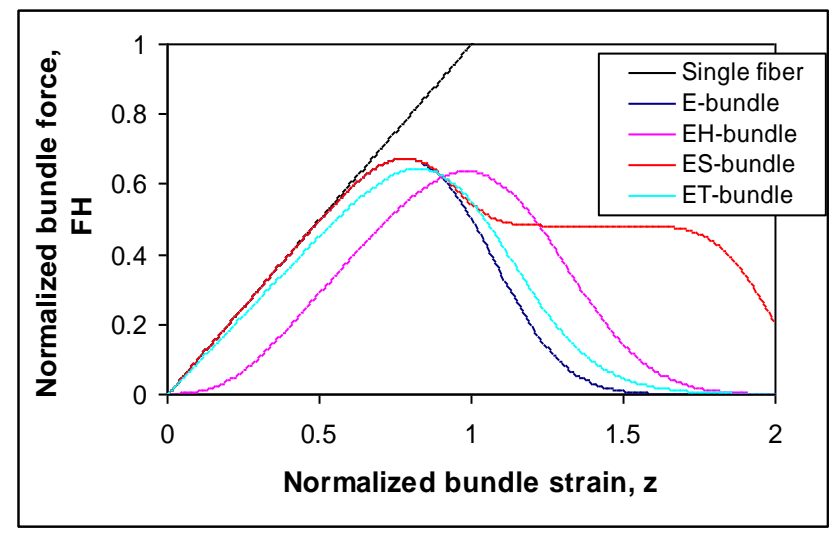

Figure 3

Expected value of typical normalized force-strain curves of the FBCs

\section{Parallel and Serial Connection of Fiber-Bundle-Cells as FBC Models}

In general, several types of FBCs are needed to model the response of a real fibrous structure. In most cases the parallel connected FBCs (Fig. 4a), called a composite bundle, provide a suitable model, and the resultant expected value process is calculated as the weighted sum of the single FBC responses where the weights are the fiber number ratios [4-10]. In the case where the size effect, such as the gauge length on strength, are examined, serial connection of the same type of independent FBCs is suitable to use in creating a bundle chain (Fig. 4b) [9, 11, 16].

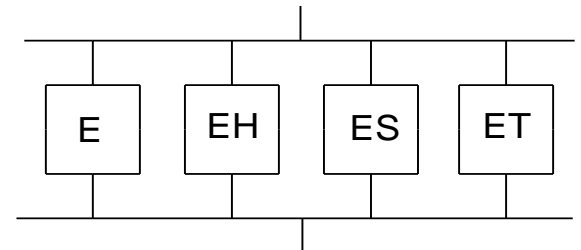

(a)

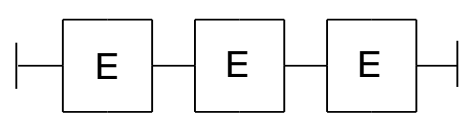

(b)

Figure 4

(a) Parallel and (b) serial connections of FBCs 
As the examples in Fig. 5a show, the weighted sum of the normalized force-strain curves visible in Fig. 3 (percentages are the relative weight values of FBCs), while in Fig. 5b, the effect of the number $(\mathrm{m})$ of serial connected E-bundles is demonstrated, causing the decrease of the peak value of the resultant force-strain curves that characterizes the tensile strength of the E-bundle chain (VE is the relative standard deviation of $\varepsilon_{\mathrm{S}}$ ).

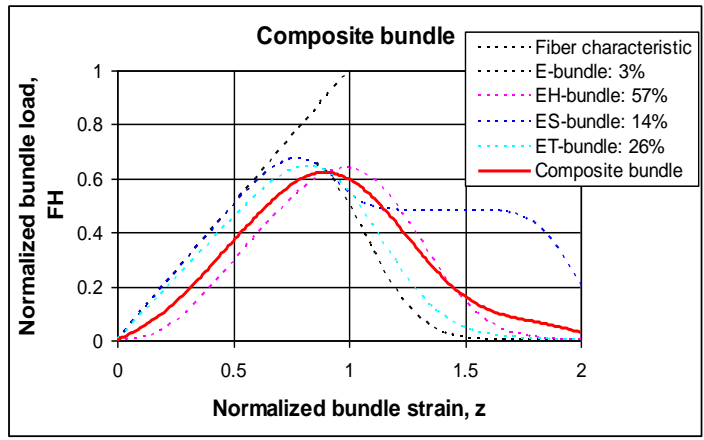

(a)

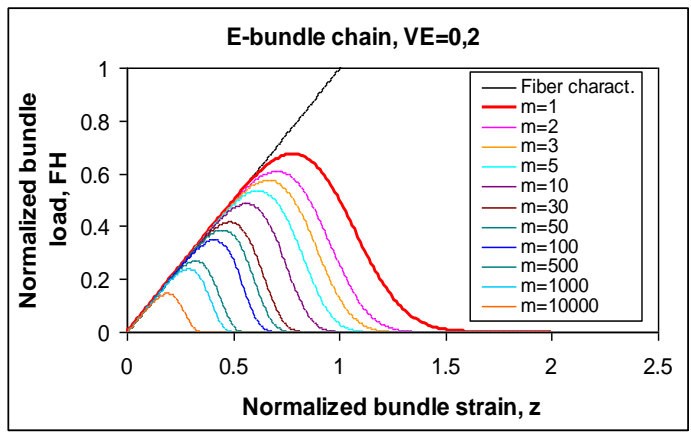

(b)

Figure 5

Normalized mean force-strain curves of parallel (a) and serial (b) connected FBCs

\section{Structural Properties of Fabric Samples}

Let us consider a rectangle sample with length $L_{o}$ and breadth $B_{o}$ cut out of the fabric in direction $\alpha$ where $\alpha=0^{\circ}$ and $\alpha=90^{\circ}$ are for the weft and warp directions, respectively (Fig. 6). Consequently, $\alpha$ is the angle of weft yarns to the length direction of the sample and the warp yarns are perpendicular to the weft direction $(\alpha+\beta=\pi / 2)$. 


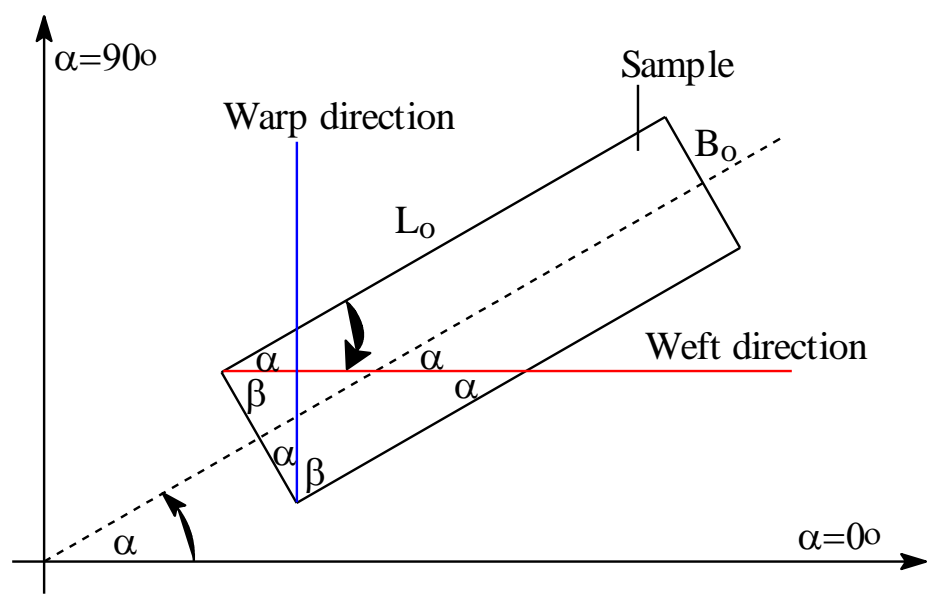

Figure 6

Disposition of a sample to the main structural directions of the fabric

The fabric sample is set for tensile test where it is gripped at the ends of $B_{0}$ breadth, and $\mathrm{L}_{0}$ (assuming $\mathrm{B}_{0} \leq \mathrm{L}_{0}$, as is usual in practice) is the free or gauge length of it; that is, $\mathrm{L}_{\mathrm{o}}$ does not include the parts needed for gripping, as can be seen in Fig. 7.

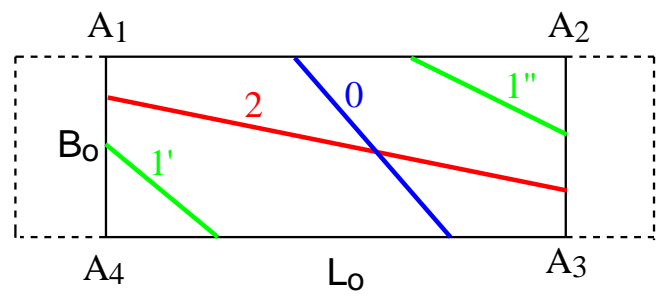

Figure 7

Classification of yarns according to their gripping position

The edges of the gripped part of the specimen bounding the free length, $\overline{A_{1} A_{4}}$ and $\overline{A_{2} A_{3}}$, can be called gripping lines. The yarns in the sample show different mechanical behavior according to the number of their gripped ends at the gripping lines (Fig. 7):

- 2-gripped yarns are gripped at both of their ends;

- 1-gripped yarns are gripped at one of their ends;

- 0-gripped yarns are not gripped at any of their ends. 


\section{Concept of Modeling Fabric Samples Using Fiber- Bundle-Cells}

As a first step in the modeling, the tensile behavior of samples cut out in the main structural directions of the fabric will be tested and analyzed by using the FBC modeling method neglecting the crimping of yarns, as in the usual finite element layer models.

The expected value of the tensile force process of the E-bundle (Figs. 1-3) related to a single yarn (in the direction of the tensile load) can be calculated by the following formula [4]:

$$
F(u)=E[F(u)]=K u\left(1-Q_{\varepsilon_{S}}(u)\right)
$$

where $u$ is the bundle strain, $K$ is the mean tensile stiffness of the yarns, and $Q_{\varepsilon s}$ is the distribution functions of the breaking strain. The yarn parameters can be determined by tensile tests of yarn samples of gauge length $L_{o}$. Using the formulas according to Equation (1) for normalizing Equation (2), we obtain:

$$
F H\left(z ; L_{O}\right)=z\left(1-Q_{\varepsilon_{S}}\left(z \bar{\varepsilon}_{S}\left(L_{O}\right)\right)\right)=\kappa(z) R H\left(z ; L_{O}\right)
$$

where the expected tensile characteristic $(\kappa)$ and the reliability function $(R H)$ of the E-bundle are defined by Equation (3).

All this is valid for gauge length $L_{o}$ at which the tensile test is performed, and it is well known that the tensile strength parameters of yarns depend on the gauge length $[2,3]$. Supposing the gauge length is changed for $L=n L_{o}(\mathrm{n}=1,2, \ldots)$ and the section of fibers of length $L_{o}$ create a so called bundle chain of independent elements (Fig. 4a), then the normalized expected tensile process of an E-bundle created by fibers of length $L$ can be calculated as follows [16] (Fig. 5b):

$$
F H(z ; L)=z\left(1-Q_{\varepsilon_{S}(L)}\left(z \varepsilon_{S}(L)\right)\right)=z\left(1-Q_{\varepsilon_{S}\left(L_{o}\right)}\left(z \varepsilon_{S}\left(L_{o}\right)\right)\right)^{L / L_{o}}
$$

It can be noted that formula (4) can be extended for $L<L_{\mathrm{o}}$ as well. Consequently, the following relationship can be obtained, which is valid for both $0<L<L_{\mathrm{o}}$ and $L \geq L_{\mathrm{o}}$ :

$$
\left(\frac{\mathrm{FH}\left(\mathrm{z} ; \mathrm{L}_{\mathrm{O}} / \mathrm{n}\right)}{\mathrm{z}}\right)^{\mathrm{n}}=\frac{\mathrm{FH}\left(\mathrm{z} ; \mathrm{L}_{\mathrm{O}}\right)}{\mathrm{z}}
$$

According to both modeling and experience, the mean breaking force of yarns and its standard deviation increase with a reduction in the gauge length, which is known as size effect in the literature $[3,16]$. 


\section{Application of the FBC Modell}

\subsection{Experimental}

\section{Material Tested}

To demonstrate the applicability of the FBC model of fabric samples, a plain woven cotton fabric and its yarn components were tested (Table 1).

Table 1

Data of the examined fabric

\begin{tabular}{|c|c|c|c|c|c|c|c|c|c|c|}
\hline \multirow[t]{2}{*}{ Material } & \multicolumn{2}{|c|}{ Type } & \multirow[t]{2}{*}{$\begin{array}{l}\text { Weight } \\
{\left[\mathrm{g} / \mathrm{m}^{2}\right]}\end{array}$} & \multirow[t]{2}{*}{$\begin{array}{l}\text { Type } \\
\text { of } \\
\text { weave }\end{array}$} & \multicolumn{2}{|c|}{$\begin{array}{l}\text { Yarn count } \\
\text { [tex] }\end{array}$} & \multicolumn{2}{|c|}{$\begin{array}{c}\text { Number of } \\
\text { yarns } \\
\lambda[1 / \mathrm{cm}] \\
\end{array}$} & \multicolumn{2}{|c|}{$\begin{array}{c}\text { Twist } \\
\text { direction of } \\
\text { yarns } \\
\end{array}$} \\
\hline & warp & weft & & & warp & weft & warp & weft & warp & weft \\
\hline Cotton & $\begin{array}{l}\mathrm{OE} \\
\text { rotor }\end{array}$ & $\begin{array}{l}\mathrm{OE} \\
\text { rotor }\end{array}$ & 156 & Plain & 29.6 & 29.6 & 26 & 22 & Z & Z \\
\hline
\end{tabular}

Tensile Tests Results

The weft and warp yarns were examined by tensile testing using a gauge length of $50 \mathrm{~mm}$, as is used normal, e.g. on the KES System. The test speed and the pretension were $12 \mathrm{~mm} / \mathrm{min}$ and $0.2 \mathrm{cN}$, respectively. The results are summarized in Table 2.

Table 2

Tensile test result of yarn

\begin{tabular}{|l|c|c|c|}
\hline \multirow{2}{*}{$\begin{array}{c}\text { Statistical } \\
\text { properties }\end{array}$} & \multicolumn{3}{|c|}{ Yarn (29.6 tex, Z twist) } \\
\cline { 2 - 4 } & Force [cN] & Elongation [mm] & Strain [\%] \\
\cline { 2 - 4 } & 272.4 & 3.24 & 6.5 \\
\hline Mean & 32.3 & 0.35 & 0.7 \\
\hline S.D. & 11.9 & 10.76 & 10.8 \\
\hline C. of V. [\%] & \multicolumn{2}{|c|}{ Cordinates of the breaking point } \\
\hline
\end{tabular}

Finally, tensile tests were carried out on fabric samples (Table 3) cut out in main directions (weft and warp) with a breadth of 50 using tensile tester Zwick Z50. The gauge length and the test speed were $50 \mathrm{~mm}$ and $12 \mathrm{~mm} / \mathrm{min}$, respectively.

The strength data are summarized in Table 3, where MaxF denotes the peak value of any load-elongation curve that is the breaking force, and the averaged curve was calculated by averaging the single load-elongation measurements point by point. 
Table 3

Tensile test results of fabric samples

\begin{tabular}{|c|c|c|c|c|}
\hline \multicolumn{5}{|c|}{ Fabric P - Breadth: $50 \mathrm{~mm}$} \\
\hline & \multicolumn{3}{|c|}{ Measured } & \multirow{2}{*}{$\begin{array}{c}\text { Averaged } \\
\text { curve }\end{array}$} \\
\hline & weft_1 & weft_2 & weft_3 & \\
\hline $\operatorname{MaxF}[\mathrm{N}]$ & $418, \overline{5}$ & 432,8 & 412,9 & 380,9 \\
\hline$\Delta l(\operatorname{maxF})[\mathrm{mm}]$ & 7,31 & 8,05 & 7,82 & 7,31 \\
\hline \multirow[t]{3}{*}{$\varepsilon(\max F)[\%]$} & 14,62 & 16,10 & 15,64 & 14,62 \\
\hline & & & & \multirow{2}{*}{$\begin{array}{c}\text { Averaged } \\
\text { curve }\end{array}$} \\
\hline & warp_1 & warp_2 & warp_3 & \\
\hline $\operatorname{MaxF}[\mathbf{N}]$ & 492,0 & 480,0 & 500,7 & 472,4 \\
\hline$\Delta l(\max F)[\mathrm{mm}]$ & 8,36 & 8,83 & 8,82 & 8,41 \\
\hline$\varepsilon(\max F)[\%]$ & 16,72 & 17,66 & 17,63 & 16,82 \\
\hline
\end{tabular}

\subsection{Results of FBC Modeling}

The results of tensile measurements performed on fabric $\mathrm{P}$ in the main structural directions and its yarn component form the experimental background of the FBC modeling.

Cutting out a sample in weft direction from the fabric means that the sample is built of weft yarns aligned lengthwise and warp yarns aligned crosswise (Fig. 8b). Loading this sample in lengthwise direction, the load is taken up by the 2-gripped weft yarns, and the 0-gripped warp yarns play just a modifying role by interlacing the weft yarns even if densely. In the present paper, the effect of interlacing is taken into account as a kind of adhesion between the yarns, that plays an important role in the cases of 1- or 0-gripped yarns, but it can be neglected for the 2-gripped yarns.

a.) E-bundle

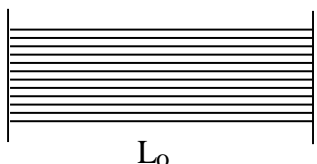

$\mathrm{L}_{0}$ b.) Fabric sample

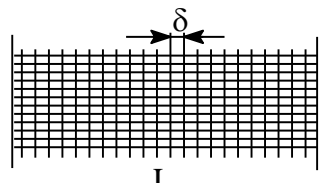

$\mathrm{L}_{\mathrm{o}}$ c.) E-bundle chain

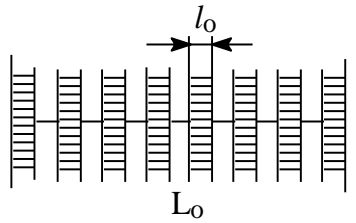

Figure 8

E-bundle (a), a fabric sample cut out in main direction (b) and E-bundle chain (c) as the model of the sample

Consequently, in a rough view, the sample cut out in main direction creates a bundle of 2-gripped yarns with an orientation angle of zero; therefore it can be modeled by a simple E-bundle (Fig. 8a). 
The normalized expected tensile force process related to a single yarn of an Ebundle is given by Equation (3). The number of yarns loaded is determined by the yarn densities $\left(\lambda_{\mathrm{ok}}, \mathrm{k}=1,2\right)$ (Table 2 ), which by multiplying with formula (3) provides the FBC estimation of tensile force recorded during a tensile test of a sample cut out in the weft $(\mathrm{k}=1)$ or warp $(\mathrm{k}=2)$ direction:

$$
\begin{aligned}
E[F(u)] & =E\left[F_{k}(u)\right]=\lambda_{o k} B_{o} E\left[F^{(k)} 1(u)\right]= \\
& =\lambda_{o k} B_{o} F_{S}^{(k)} z\left(1-Q_{\varepsilon_{S}}^{(k)}\left(\varepsilon_{S}^{(k)} z\right)\right)=\lambda_{o k} B_{o} F_{S}^{(k)} F H^{(k)}(z)
\end{aligned}
$$

This is valid in the case of an E-bundle built up of yarns of given length $L_{o}$.

Modeling Software FiberSpace is suitable for providing $F H^{(\mathrm{k})}(z)$ because this simple model does not contain any combined FBC. For modeling - in this simple case - just the mean and CV of the breaking strain of the yarn are needed, which can be found in Table 2 . They are respectively denoted by AE $(=0.0648)$ and VE $(=0.108)$ in Fiber Space.

The results of modeling the E-bundle of $\mathrm{L}_{0}=50 \mathrm{~mm}$ yarns - which was imported to Microsoft Excel - can be seen in Fig. $10\left(\mathrm{~L}=\mathrm{L}_{\mathrm{o}}=50 \mathrm{~mm}\right)$. This expected tensile force process can be approximated by averaging point-by-point measured and normalized force-strain curves. According to Fig. 10, the expected yarn strength efficiency (which is determined by the peak value of the normalized curve) in the fabric sample in main direction is 0.782 , that is $78.2 \%$. This is valid for both weft and warp directions because of the identical weft and warp yarns and the symmetric structure of a plain weave.

The estimated expected tensile strength in both directions can be calculated by using Equation (6). As is usual according to the related standards, the breadth of the sample was taken as $B_{0}=50 \mathrm{~mm}$ (Table 4).

The strength values in Table 4 are considered 'ideal' when they were calculated as the simple product of the number of yarn in the direction of load and the mean yarn strength, and the 'realistic' ones were obtained by multiplying the latter by the expected yarn strength utilization provided by modeling the bundle of yarns of $50 \mathrm{~mm}$ length (Fig. 8a).

On the basis of Table 4, it can be stated that the measured tensile strength values proved to be larger than the estimations denoted by 'ideal' or 'realistic'. This can be explained by two facts:

(1) The mean tensile strength of yarns strongly depends on the gauge length used (size effect); the smaller it is, the larger the mean strength is [1-3, 16].

(2) The crosswise yarns create a kind of gripping for the tensile loaded yarns, sectioning them into short E-bundles which form a so-called E-bundle chain (Fig. 8c) [16]. The effective length of these bundles $\left(l_{0}\right.$; Fig. 8c) can be larger than the distance between the crosswise yarns $(\delta$; Fig. $8 \mathrm{~b})$ because of the possibility of some slippage and the strain of yarns at the peak force. 
Table 4

Results of FBC modeling using yarns of $50 \mathrm{~mm}$ length and measurements (mean)

\begin{tabular}{|l|c|c|c|}
\hline & Estimation & $\begin{array}{c}\text { Weft } \\
\text { direction }\end{array}$ & $\begin{array}{c}\text { Warp } \\
\text { direction }\end{array}$ \\
\hline Yarn strength utilization [\%] & real & 78.2 & 78.2 \\
\hline Fabric tensile strength & ideal & 300 & 354 \\
\cline { 2 - 4 } calculated for 50 mm width [N] & realistic & 234 & 277 \\
\hline $\begin{array}{l}\text { Fabric tensile strength measured } \\
\text { at 50 mm width [N] }\end{array}$ & ---- & 381 & 472 \\
\hline
\end{tabular}

The mean strength of these short E-bundles can be much greater than that of the longer, but the standard deviation of these short yarn segments is larger as well. The strength of this bundle chain is determined by the "weakest link" [2], yet this minimum value can be significantly larger than that of the original bundle of long yarns.

Regarding the breaking force only, suppose all the yarn breakages take place in a single short bundle (Fig. 9a), meaning that the other bundles are subjected to strain only and the model of this behavior can be represented by a short E-bundle and a serial connected elastic continuum part (Fig. 9b).

In this case, the force-elongation relation is governed by the E-bundle, and the role of the elastic part is to model the surplus in elongation as the contribution of the other bundles. In this model, reaching the peak force value of the bundle, the breakage of the chain can occur in a catastrophic way if the breaking bundle cannot cover the loss in elongation after the bundle force peak [16]. These drops in force can take place after each other if the yarn breakages are distributed over several bundles of the chain.

As the other extreme case, the breakages of single yarns can be evenly distributed over the chain, realizing an expected tensile process identical with that of the single bundles [16].

In reality, the damage and failure process is realized as one between the two extreme damage cases. In addition, the yarn chain that is a bundle chain which consists of a single yarn can be treated as a lower estimation of the real one [16].

a.)

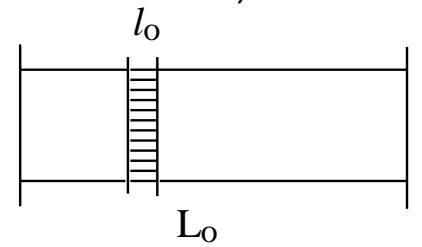

b.)

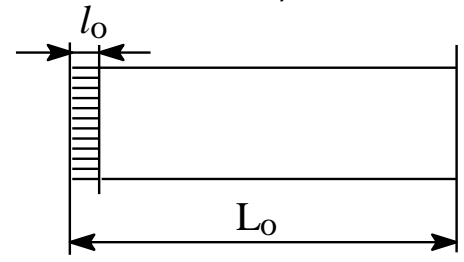

Figure 9

Fabric sample as the serial connection of a single breaking E-bundle and an elastic part 
In the sense of the "weakest link" concept, Equation (4) describes the expected tensile force process of an E-bundle chain where the number of E-bundle is $n=L / L_{o}$. In this case, the peak value and the half-width of the force-chain curve (corresponding to the standard deviation of the yarns) decrease by increasing $n$ or $L$ (Fig. 10). At the same time, concerning the tensile strength, the E-bundle chain can be considered as a single E-bundle built up of yarns of length $L$. In this sense Equation (4) can be used for bundles of yarns of length smaller than $L_{o}$ as well. In the latter case, the peak value and the half-width increase (Fig. 10).

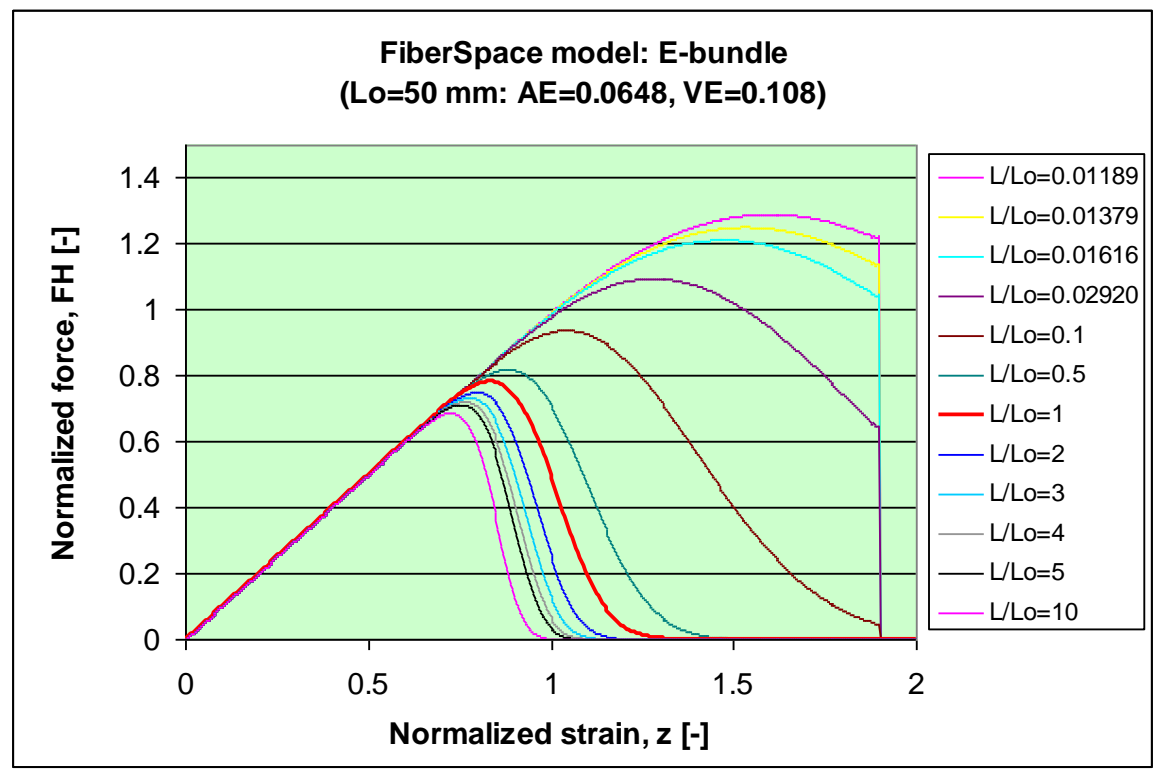

Figure 10

Normalized expected force-strain curves of E-bundles with different relative lengths $\left(L / L_{o}\right)$

In this extended sense, Fig. 11 shows the normalized peak force values as a function of the yarn length, which is the gauge length of the yarns $(L)$ in logarithmic scale.

The results of modeling discussed above give a good basis for analyzing the measurements obtained by tensile test of fabric samples. Since our simple FBC modeling method applies E-bundles only consequently, the so called structural elongation caused by the crimping of the yarns and the elastic pulling out of the grips are not modeled, and therefore the first step of the analysis is the determination of the structural elongation.

This is defined by the steepest tangent straight line belonging to the inflexion point of the rising part of the force-elongation curve. The structural elongation is determined by the intersection point of the tangent and the elongation axis (Fig. $11)$. 


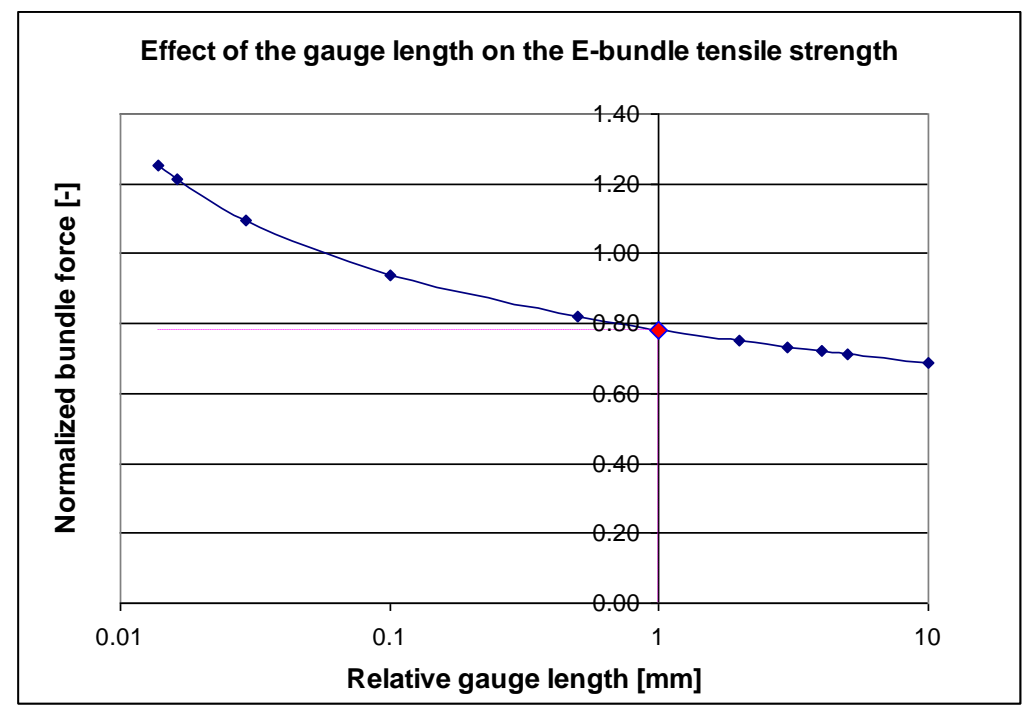

Figure 11

Peak values of E-bundles versus relative yarn length in logarithmic scale

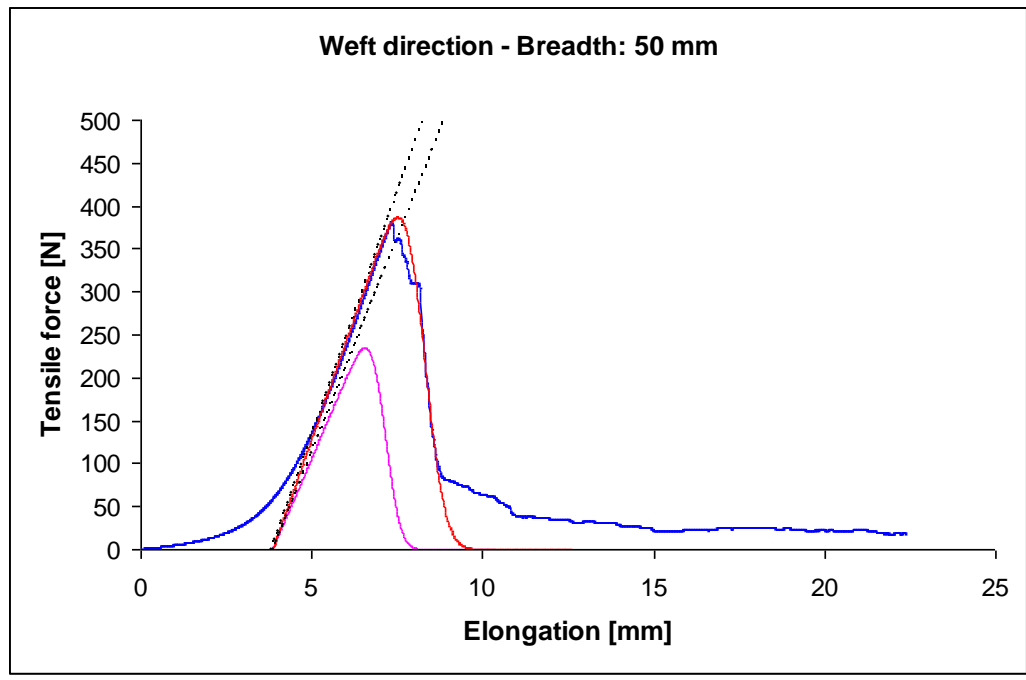

Figure 12

Measured and averaged force-elongation curve (blue line), shifted E-bundle curve (lilac line), and the transformed model curve (red line) for samples cut out of weft direction 


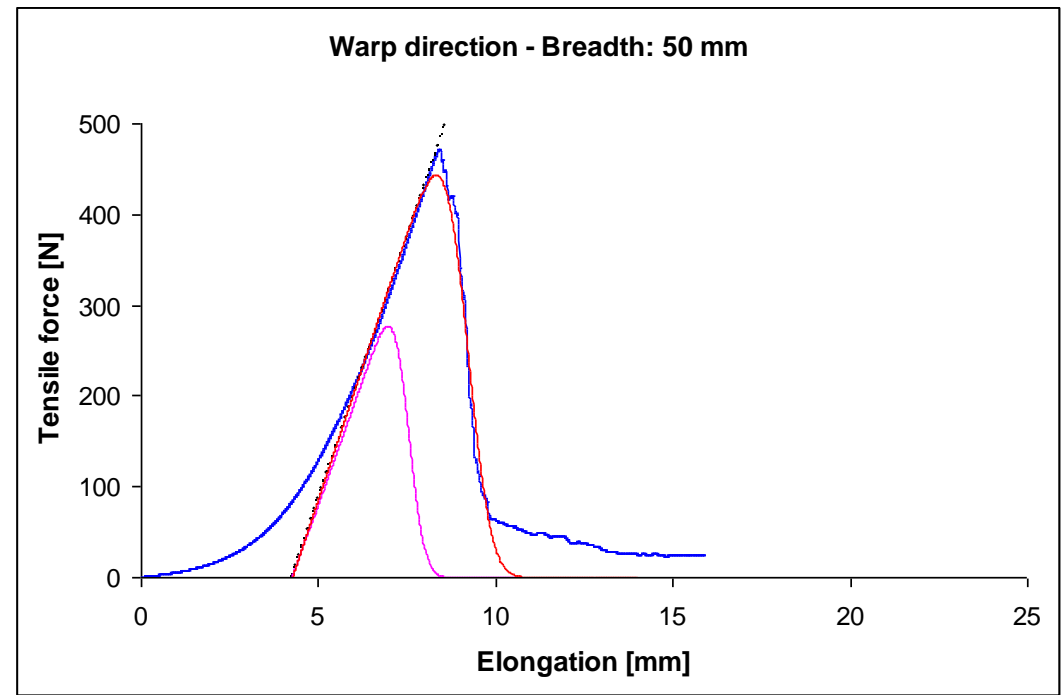

Figure 13

Measured and averaged force-elongation curve (blue line), shifted E-bundle curve (lilac line), and the transformed model curve (red line) for samples cut out of warp direction

Table 5

Results of FBC analysis based on E-bundle model

\begin{tabular}{|c|c|c|c|c|}
\hline $\begin{array}{c}\text { Sample } \\
\text { width } \\
L_{o} \\
{[\mathrm{~mm}]} \\
\end{array}$ & $\begin{array}{l}\text { Origin of } \\
\text { result }\end{array}$ & Properties & Weft & Warp \\
\hline \multirow{14}{*}{50} & \multirow{4}{*}{ Measured } & Size of weave cell $\delta[\mathrm{mm}]$ & 0.4545 & 0.3846 \\
\hline & & Tensile strength $[\mathrm{N}]$ & 380.9 & 472.4 \\
\hline & & Tensile stiffness $[\mathrm{N} / \mathrm{mm}]$ & 113 & 115 \\
\hline & & Structural elongation $[\mathrm{mm}]$ & 3.85 & 4.26 \\
\hline & \multirow{3}{*}{$\begin{array}{l}\text { Modeled } \\
\text { by yarns }\end{array}$} & Max force $[\mathrm{N}]$ & 234.4 & 277.0 \\
\hline & & Tensile stiffness $[\mathrm{N} / \mathrm{mm}]$ & 100 & 115 \\
\hline & & Yarn strength utilization [\%] & 78.21 & 78.21 \\
\hline & \multirow{7}{*}{$\begin{array}{l}\text { Shifted } \\
\text { and } \\
\text { scaled } \\
\text { model }\end{array}$} & Scale factor of elongation [-] & 1.35 & 1.50 \\
\hline & & Scale factor of force $[-]$ & 1.65 & 1.60 \\
\hline & & Max force $[\mathrm{N}]$ & 386.7 & 443.2 \\
\hline & & Yarn strength utilization [\%] & 1.29 & 1.2514 \\
\hline & & Length ratio, $\mathrm{n}=l_{\mathrm{o}} / \mathrm{L}_{\mathrm{o}}$ & 0.01190 & 0.01379 \\
\hline & & Effective bundle length, $l_{\mathrm{o}}[\mathrm{mm}]$ & 0.5945 & 0.6897 \\
\hline & & Relative eff. bundle length, $l_{o} / \delta[-]$ & 1.31 & 1.79 \\
\hline
\end{tabular}


Figs. 12 and 13 show the measured and averaged force-elongation curves (blue lines) and the steepest tangents.

In these diagrams the E-bundle model curves (lilac lines) with their initial tangent are shifted from the origin by the structural elongation.

It can be seen in the diagrams (Figs. 12,13) that the linear variable transformation (which is applying the proper scaling) of these shifted E-bundle curves (red lines) fits well to the measured ones regarding both the rising and the falling branches of the curves.

The results of the measurements and modeling and model based analysis are summarized in Table 5.

\section{Conclusions}

On the basis of the diagrams and numerical results some essential statements can be made.

(1) The structural elongation caused by the interlacing and crimping of the yarns adding to that the elastic pulling out of the grips is rather large (about $8 \%$ ).

(2) The large measured structural elongation means that it is important to take into account for modeling the deformation and, e.g., the drape behavior of the fabric.

(3) The yarn strength utilization of ideal E-bundle consisting of independent yarns of $50 \mathrm{~mm}$ length is $78.2 \%$, which is relatively small. The measured utilization was larger than $100 \%$, meaning that the interlaced crosswise yarns bind together the segments of the loaded yarns, forcing them strongly to work together, and by that, a relatively small effective length is realized that is much smaller than the gauge length of the fabric sample.

(4) The effective bundle length values $\left(l_{o}\right)$ determined by the shifted and rescaled E-bundle curves using Equation (4) are larger than the weave cell sizes $(\delta)$, indicating that the crosswise interlacing yarns can slip on the loaded ones causing an increase in the bundle length.

(5) The slippage of interlacing yarns given by the positive difference $l_{o}$ - $\delta$ (see Table 5), which is in relation with certain friction and shear effects, indicates that it can also be an important factor in modeling the deformation and drape behavior of fabrics.

On the basis of these results, the E-bundle based modeling of the tensile strip test of fabrics in the main directions can be well used for analyzing the tensile measurements and the structural-mechanical behavior of fabric specimens tested.

\section{Acknowledgements}

This work was supported by the Hungarian Scientific Research Fund (OTKA, H), the National Development Agency (NDA, H), and the Scientific and 
Technological Research Council of Turkey (TÜBİTAK, TR) since this multinational study has been carried out commonly as part of the project K68438 (OTKA-NDA), as well as of the S\&T projects 108M604 (TÜBİTAK) and TR$17 / 2008$ (NDA) respectively. This project is also supported by the New Széchenyi Plan (Project ID: TÁMOP-4.2.1/B-09/1/KMR-2010-0002) and connected to the scientific program of the "Development of quality-oriented and harmonized $\mathrm{R}+\mathrm{D}+\mathrm{I}$ strategy and functional model at BME" project.

\section{References}

[1] Harlow D. G., Phoenix S. L.: The Chain-of-Bundles Probability Model For the Strength of Fibrous Materials I: Analysis and Conjectures. Journal of Composite Materials Vol. 12, 195-214, and The Chain-of-Bundles Probability Model For the Strength of Fibrous Materials II: A Numerical Study of Convergence. Journal of Composite Materials Vol. 12, 314-334 (1978)

[2] Peirce F. T.: Tensile Tests for Cotton Yarns. Part V The Weakest Link, Theorem on the Strength of Long and Composite Specimens. Journal of The Textile Institute Transactions 17(7) T355-T368 (1926)

[3] Sutherland L. S., Shenoi R. A., Lewis S. M.: Size and Scale Effects in Composites: I. Literature Review. Composites Science and Technology 59, 209-220 (1999)

[4] Vas L. M., Császi F.: Use of Composite-Bundle Theory to Predict Tensile Properties of Yarns. Journal of the Textile Institute 84(3), 448-463 (1993)

[5] Vas L. M., Halász G.: Modelling the Breaking Process of Twisted Fibre Bundles and Yarns. Periodica Polytechnica 38(4), 297-324 (1994)

[6] Vas L. M.: Strength of Unidirectional Short Fiber Structures as a Function of Fiber Length. Journal of Composite Materials 40(19), 1695-1734 (2006)

[7] Vas L. M., Rácz Zs.: Modeling and Testing the Fracture Process of Impregnated Carbon Fiber Roving Specimens During Bending Part I. Fiber Bundle Model. Journal of Composite Materials 38 (20), 1757-1785 (2004)

[8] Vas L. M.: Statistical Modeling of Unidirectional Fiber Structures. Macromolecular Symposia. Special Issue: Advanced Polymer Composites and Technologies 239(1), 159-175 (2006)

[9] Vas L. M., Tamás P.: Modelling Method Based on Idealised Fibre Bundles. Plastics, Rubber and Composites 37(5/6) 233-239 (2008)

[10] Molnár K., Vas L. M., Czigany T.: Determination of Tensile Strength of Electrospun Single Nanofibers through Modeling Tensile Behavior of the Nanofibrous Mat. Composites Part B 43 (2012) 15-21 DOI: 10.1016/j.compositesb.2011.04.024 (2012) 
[11] Vas L. M., Tamás P.: Fiber-Bundle-Cells Method and its Application to Modeling Fibrous Structures, GÉPÉSZET 2006, $5^{\text {th }}$ Conf. on Mech. Eng. Budapest, May 25-26, 2006. Proceedings (CD - Full-text) ISBN 9635934653 (2006)

[12] Vas L. M., Tamás P.: Modeling Fibrous Reinforcements and Composites Using Fiber Bundle Cells, III. International Technical Textiles Congress Dec. 1-2, 2007 Istanbul, Proceedings 95-104 ISBN 978-975-441-245-1 (2007)

[13] Tamás P., Vas L. M.: Modelling Fibrous Structures by FiberSpace Using Fourier Transformation Based Expert Program. GÉPÉSZET 2008, $6^{\text {th }}$ Conf. on Mech. Eng. Budapest, May 28-29, 2008, Proceedings (CD - Fulltext) ISBN 9789634209478 (2008)

[14] Tamás P., Vas L. M.: Fiber Bundle Based Modeling Software, ITC\&DC Magic World of Textiles IV International Textile, Clothing \& Design Conference Oct. 5-8, 2008 Dubrovnik, Book of Proceedings 892-897, ISBN 978-953-7105-26-6 (2008)

[15] Vas L. M., Tamás P.: Modelling Size Effects of Fibrous Materials Using Fibre-Bundle-Cells. ECCM-14 $14^{\text {th }}$ European Conference on Composite Materials, Budapest, 7-10 June, 2010, Proceedings Paper ID-705, 1-11, ISBN: 978-963-313-008-7 (2010)

[16] Vas L. M., Tamás P., Halász M., Göktepe F.: Fiber-Bundle-Cells Model of Composites. $5^{\text {th }}$ Aachen-Dresden International Textile Conference, Aachen, Germany, Nov. 24-25, 2011 (poster presentation) Proceedings ISSN 18676405 (CD edited by B. Küppers) P-15, 1-10 (2011) 